\title{
Tandem MS Can Distinguish Hyaluronic Acid from $N$-Acetylheparosan
}

\author{
Zhenqing Zhang, ${ }^{a}$ Jin Xie, ${ }^{a}$ Jian Liu, ${ }^{b}$ and Robert J. Linhardt ${ }^{\mathrm{a}}$ \\ a Departments of Chemistry and Chemical Biology, Chemical and Biological Engineering and Biology, Center \\ for Biotechnology and Interdisciplinary Studies, Rensselaer Polytechnic Institute, Troy, New York, USA \\ ${ }^{\mathrm{b}}$ Division of Medicinal Chemistry and Natural Products, School of Pharmacy University of North Carolina, \\ Chapel Hill, North Carolina, USA
}

Isobaric oligosaccharides enzymatically prepared from hyaluronic acid (HA) and $N$-acetylheparosan (NAH), were distinguished using tandem mass spectrometry. The only difference between the two series of oligosaccharides was the linkage pattern (in HA $1 \rightarrow 3$ and in NAH $1 \rightarrow 4$ ) between glucuronic acid and $N$-acetylglucosamine residues. Tandem mass spectrometry afforded spectra in which glycosidic cleavage fragment ions were observed for both HA and NAH oligosaccharides. Cross-ring cleavage ions ${ }^{0,2} A_{n}$ and ${ }^{0,2} A_{n}-h$ ( $n$ is even number) were observed only in GlcNAc residues of NAH oligosaccharides. One exception was an ${ }^{0,2} \mathrm{~A}_{2}$ ion fragment observed for the disaccharide from HA. These cross-ring cleavage fragment ions are useful to definitively distinguish HA and NAH oligosaccharides. (J Am Soc Mass Spectrom 2008, 19, 82-90) (C) 2008 American Society for Mass Spectrometry

G lycosaminoglycans (GAGs) are linear, acidic polysaccharides found on cell surfaces and in the surrounding extracellular matrix. GAGs participate in and regulate many cellular events and physiological and pathophysiological processes, such as cell proliferation and differentiation, cell-cell and cellmatrix interactions, and viral infection through their interaction with different proteins [1-3]. GAGs are divided into four main categories: hyaluronic acid or hyaluronan (HA), chondroitin/dermatan sulfate, $\mathrm{N}$ acetylheparosan (NAH)/heparan sulfate/heparin, and keratan sulfate, based on their monosaccharide composition and the configuration and position of the glycosidic bonds between these monosaccharides. The specificity of the interactions between GAGs and proteins results from structural diversity of GAGs defined by their size, saccharide composition and sequence, charge density $[4,5]$. Thus, understanding the structure of a GAG is essential in understanding its activity and biological functions. HA and NAH are biosynthesized by both prokaryotic and eukaryotic cells. HA is copolymer linked polymer of $\beta$-1,4 D-glucuronic acid (GlcA) and $\beta-1,3 \mathrm{D}-\mathrm{N}$-acetylglucosamine (GlcNAc) [6]. NAH is a copolymer of $\beta-1,4$ GlcA and $\alpha-1,4$ GlcNAc and the biosynthetic precursor of the mammalian GAGs, heparin and heparan sulfate [7]. HA can be prepared by bacterial fermentation of Streptococcus zooepidemicus [8], or enzymatically using biosynthetic enzymes prepared from Pasturella multocida [9]. Bacteria use HA as camouflage to enhance their ability to infect higher ani-

Address reprint requests to Dr. R. J. Linhardt, Departments of Chemistry and Chemical Biology, Chemical and Biological Engineering and Biology, Center for Biotechnology and Interdisciplinary Studies, Rensselaer Polytechnic Institute, 110 8th St., Troy, NY 12180, USA. E-mail: Linhar@rpi.edu mals [10]. Similarly, Escherichia coli strain K5 produces capsular polysaccharide comprised of $\mathrm{NAH}$ [11]. NAH is also important as it represents a considerable portion of the sequence of mammalian heparan sulfate $[12,13]$. HA and NAH are the two simplest GAGs since neither has sulfo groups and, thus, consist of only a single sequence (Figure 1). HA and $\mathrm{NAH}$ have very similar structures, differing only in the position of their glycosidic linkage between GlcA and GlcNAc. This difference in structure results from very different biosynthesis pathways for $\mathrm{HA}$ and NAH [14-17] and gives each polysaccharide unique biological functions and distinctive structure-activity relationships [18].

The oligosaccharides prepared from GAGs by controlled enzymatic depolymerization are often studied to define the minimum structural requirements for biological activity $[19,20]$. ESI-MS is particularly useful to monitor these GAG-derived oligosaccharides due to its soft ionization [21, 22]. LC-ESI-MS, relying on reversedphase ion-pairing (RPIP)-high-performance liquid chromatography (HPLC), has employed volatile ion-pairing reagents $[23,24]$ to successfully analyze $\mathrm{HA}$ and $\mathrm{NAH}$ [25]. Unfortunately, this method results in nearly identical retention times for the HA and NAH oligosaccharides, and since they have identical masses, it is not possible to differentiate these oligosaccharides. Most laboratories routinely rely on nuclear magnetic resonance (NMR) spectroscopy, requiring relatively large amounts of samples, to distinguish HA and $\mathrm{NAH}$ oligosaccharides [26, 27]. These two series of oligosaccharides can also be differentiated based on their susceptibilities to specific polysaccharide degrading enzymes, where the degradation can be detected by 


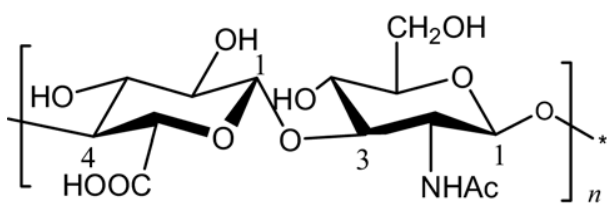

Hyaluronic acid (HA)

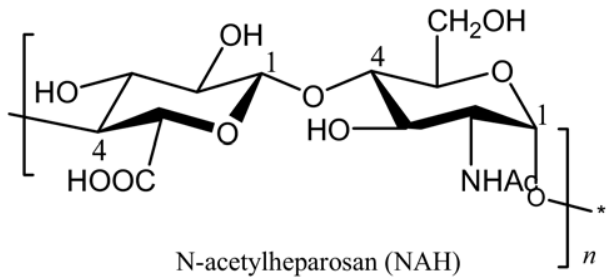

$\mathrm{N}$-acetylheparosan (NAH)

Figure 1. Structure of HA and NAH.

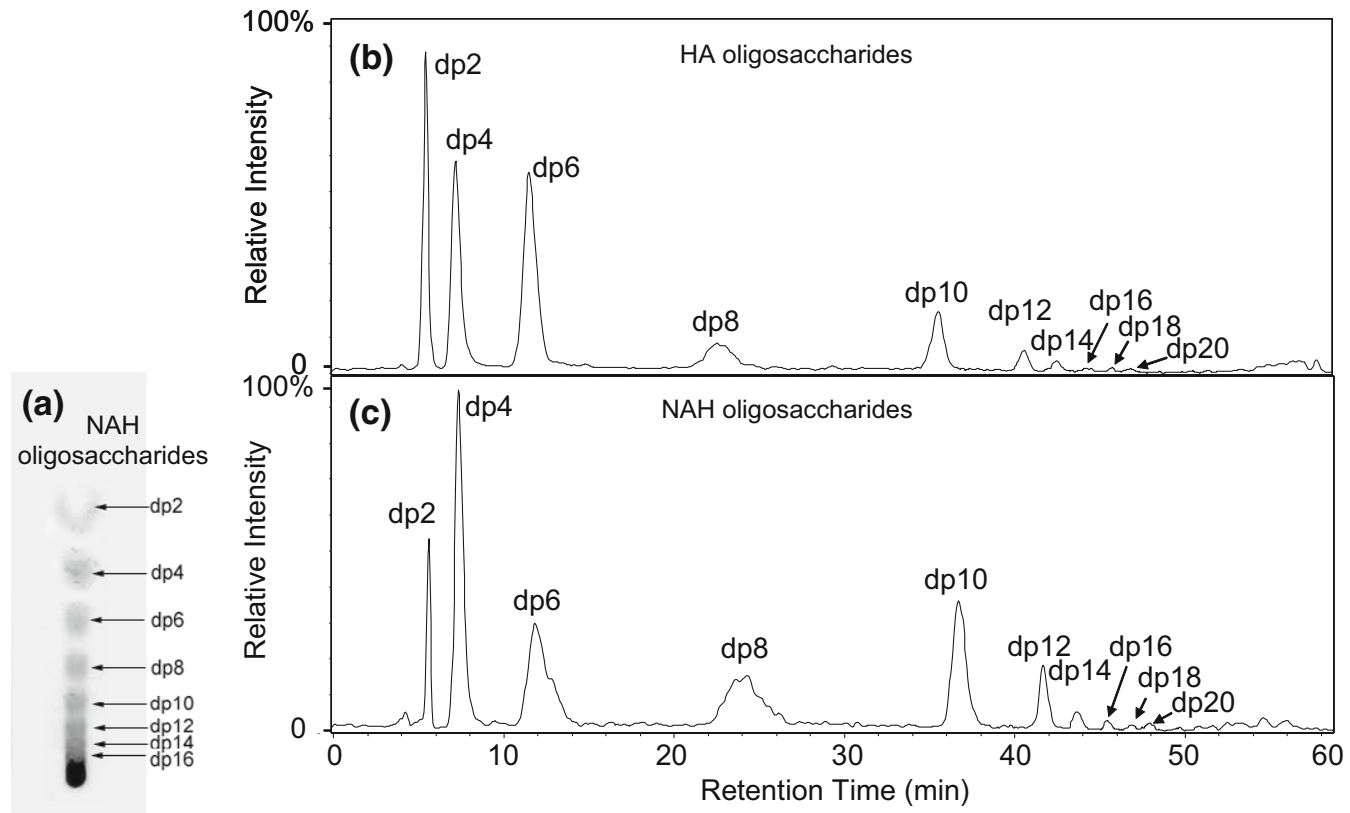

Figure 2. Total ion chromatogram (TIC) of HA oligosaccharides (a). TLC analysis of NAH oligosaccharides (b). TIC of NAH oligosaccharides (c).

ultraviolet spectroscopy (UV), HPLC, thin-layer chromatography (TLC), polyacrylamide gel electrophoresis, or change in viscosity. A new method, which could confirm the identity of polysaccharide made by small samples of new isolates containing both $\mathrm{HA}$ and $\mathrm{NAH}$, would be useful.

Tandem mass spectrometry offers a sensitive and more readily available alternative to NMR for the analysis of GAG oligosaccharides. ESI tandem MS has been previously used to analyze HA oligosaccharides and glycosidic fragment ions were previously observed with single or multiple charges [28, 29]. Unfortunately, these fragment ions would be expected to form from both HA and NAH oligosaccharides.

This article describes a method for distinguishing $\mathrm{HA}$ and NAH oligosaccharide mixtures prepared by

Table 1. Major molecular ions observed in the ESI mass spectra of HA and NAH oligosaccharides

\begin{tabular}{|c|c|c|c|c|c|c|c|}
\hline & Calculated mass & {$[2 \mathrm{M}-\mathrm{H}]^{-}$} & {$[\mathrm{M}-\mathrm{H}]^{-}$} & {$[\mathrm{M}-2 \mathrm{H}]^{2-}$} & {$[\mathrm{M}-3 \mathrm{H}]^{3-}$} & {$[\mathrm{M}-4 \mathrm{H}]^{4-}$} & {$[\mathrm{M}-5 \mathrm{H}]^{5-}$} \\
\hline dp2 & 379.1 & 757.2 & $378.1 *$ & & & & \\
\hline dp4 & 758.2 & & $757.1^{*}$ & & & & \\
\hline dp6 & 1137.3 & & 1136.3 & $567.8^{*}$ & & & \\
\hline dp8 & 1516.4 & & & $757.2^{*}$ & & & \\
\hline dp10 & 1895.5 & & & $946.8^{*}$ & 630.9 & & \\
\hline dp12 & 2274.7 & & & 1136.8 & $757.3^{*}$ & & \\
\hline dp14 & 2653.8 & & & 1326.8 & $883.8 *$ & & \\
\hline dp16 & 3032.9 & & & & 1010.3 & $757.4^{*}$ & \\
\hline dp18 & 3412.0 & & & & 1136.9 & $852.2^{*}$ & 681.5 \\
\hline dp20 & 3791.1 & & & & & $947.2^{*}$ & 757.3 \\
\hline
\end{tabular}

*Fragments marked were used as precursor ions in tandem MS. 


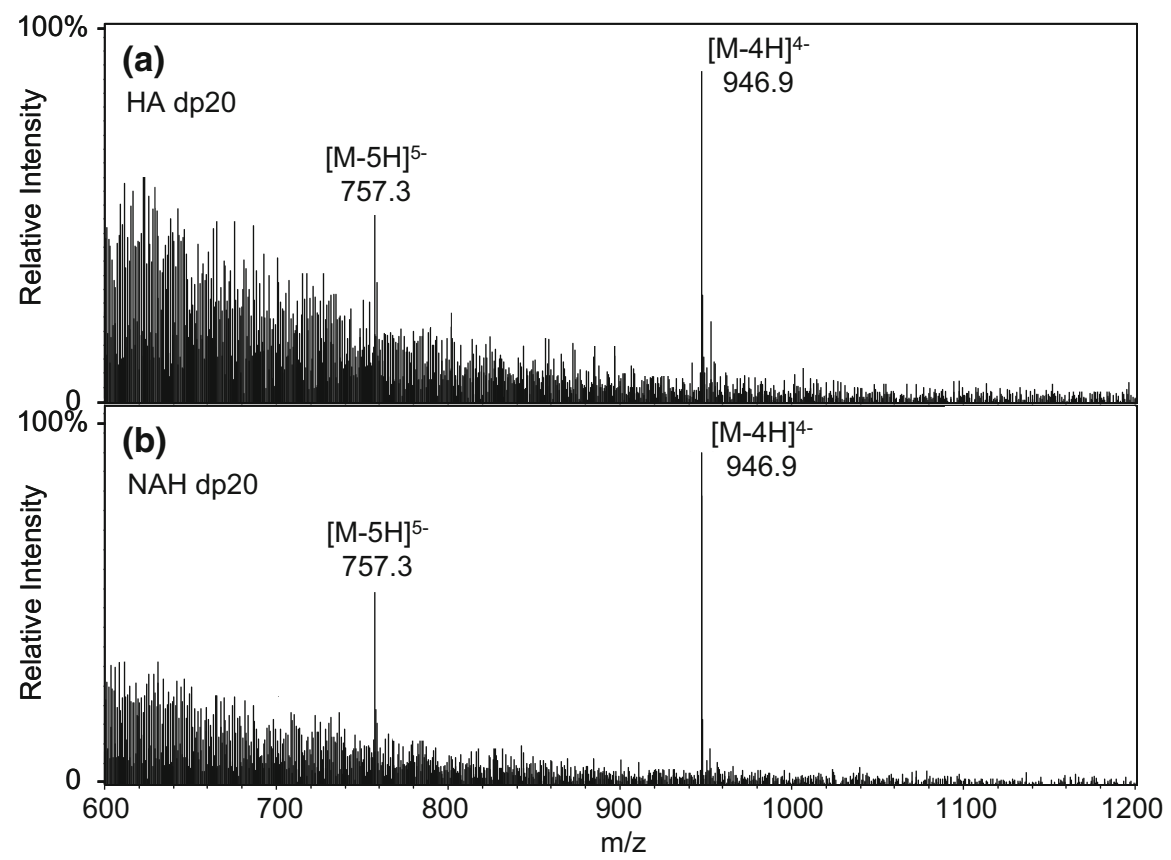

Figure 3. ESI mass spectra of dp20 of HA (a) and NAH (b).
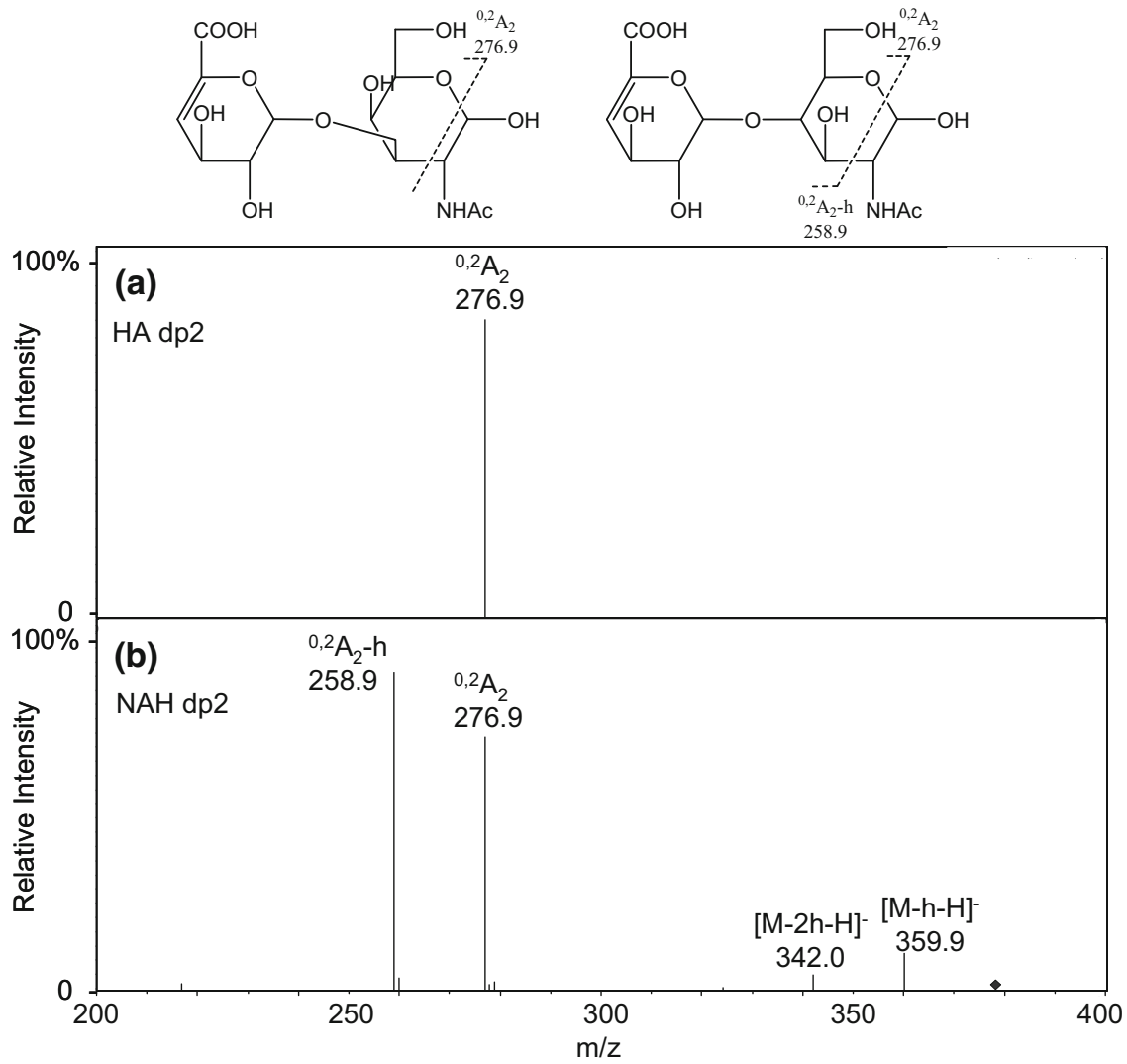

Figure 4. MS/MS spectra of disaccharides (dp2) from HA (a) and NAH (b). 

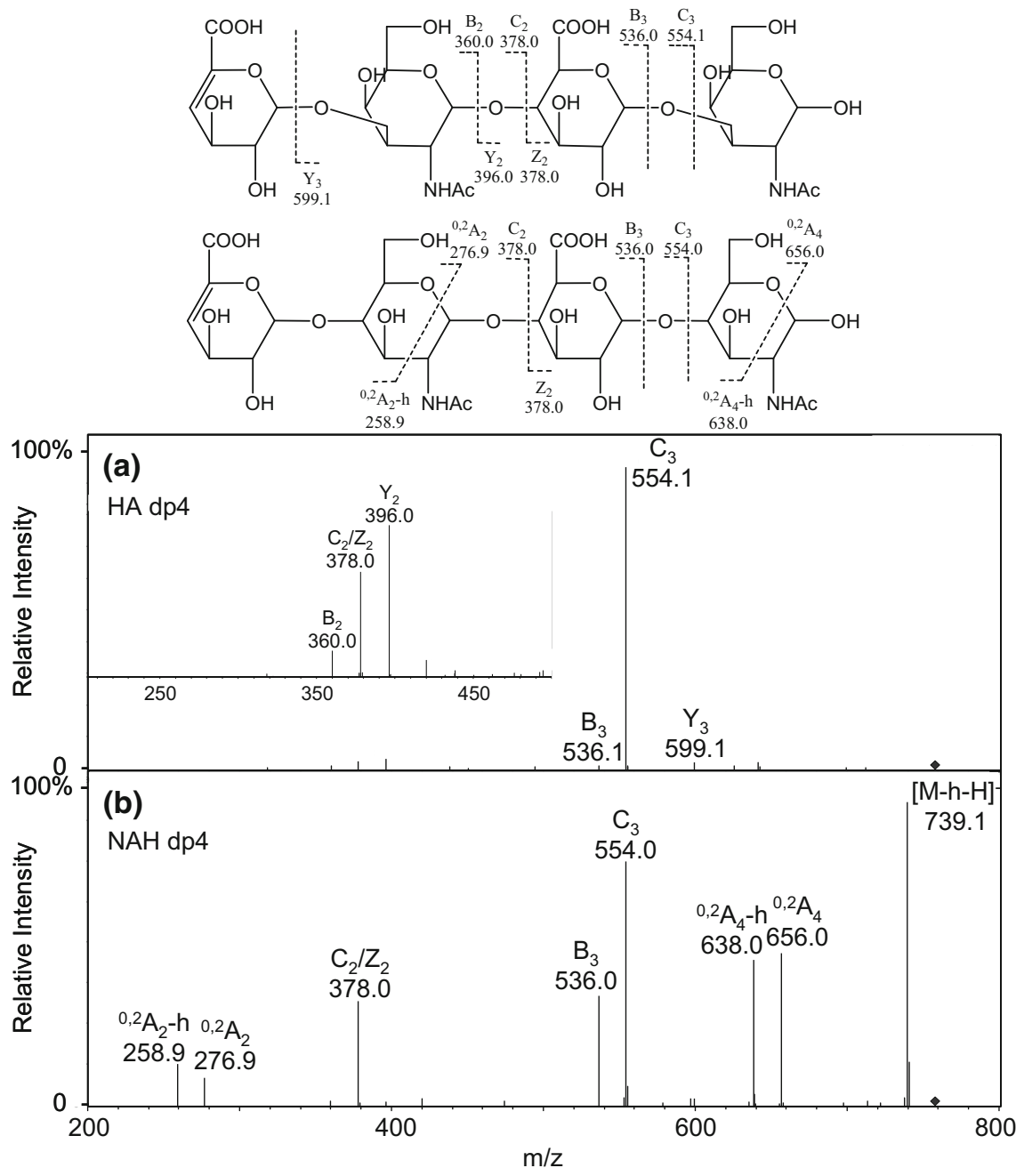

Figure 5. MS/MS spectra of tetrasaccharides (dp4) from HA (a) and NAH (b).

partial enzymatic digestion. RPIP-LC-ESI-MS and tandem MS are applied to analyze these oligosaccharides and distinguish HA and NAH oligosaccharides based on the relative abundance of their characteristic fragment ions.

\section{Materials and Methods}

\section{Preparation of Oligosaccharides Mixture}

$\mathrm{N}$-acetylheparosan (NAH) was isolated through fermentation of $E$. coli $\mathrm{K} 5$ and purified as previously described [11]. The NAH $500 \mu \mathrm{g} / 50 \mu \mathrm{L}$ was incubated in $50 \mathrm{mM}$ sodium phosphate buffer $\mathrm{pH} 7.0$ with heparin lyase III (10 m-units, Sigma Chemicals, St Louis, MO) at $37^{\circ} \mathrm{C}$ for $10 \mathrm{~h}$ with aliquots removed at various time points for analysis. The aliquots were heated in a boiling water bath for $10 \mathrm{~min}$ to halt the reaction. The denatured protein was removed by centrifugation at $12,000 \times g$ for $10 \mathrm{~min}$. Hyaluronic acid (HA, from rooster comb) was purchased from Sigma. Chondroitin lyase ABC (5 m-units, Seikagaku Biochemical, Tokyo, Japan) was used to digest HA (500 $\mu \mathrm{g} / 50 \mu \mathrm{L})$ in $50 \mathrm{mM}$ sodium phosphate buffer $\mathrm{pH} 7.0$ at $37^{\circ} \mathrm{C}$ for $10 \mathrm{~h}$ and aliquots were removed periodically and collected as described above.

\section{TLC Conditions}

The progress of the enzymatic depolymerization was monitored by measuring the HA and NAH oligosaccharides present in aliquots taken throughout the reaction by TLC on a precoated silica gel-60 aluminum plates (Merck, Darmstadt, Germany) $(1 \times 5 \mathrm{~cm})$ or $(10$ $\mathrm{cm} \times 5 \mathrm{~cm}$ ) eluted with a solvent system consisting of n-butanol/formic acid/water, 4:8:1 (vol/vol). The eluted plate was stained by dipping in a reagent containing $1 \mathrm{~mL}$ of $37.5 \% \mathrm{HCl}, 2 \mathrm{ml}$ of aniline, $10 \mathrm{~mL}$ of $85 \%$ $\mathrm{H}_{3} \mathrm{PO}_{3}, 100 \mathrm{~mL}$ of ethyl acetate and $2 \mathrm{~g}$ diphenylamine) for $3 \mathrm{~s}$ and heating at $150{ }^{\circ} \mathrm{C}$ for $10 \mathrm{~s}$ [30].

\section{LC-MS/MS}

LC MS analyses were performed on Agilent 1100 LC/ MSD instrument (Agilent Technologies, Inc. Wilming- 

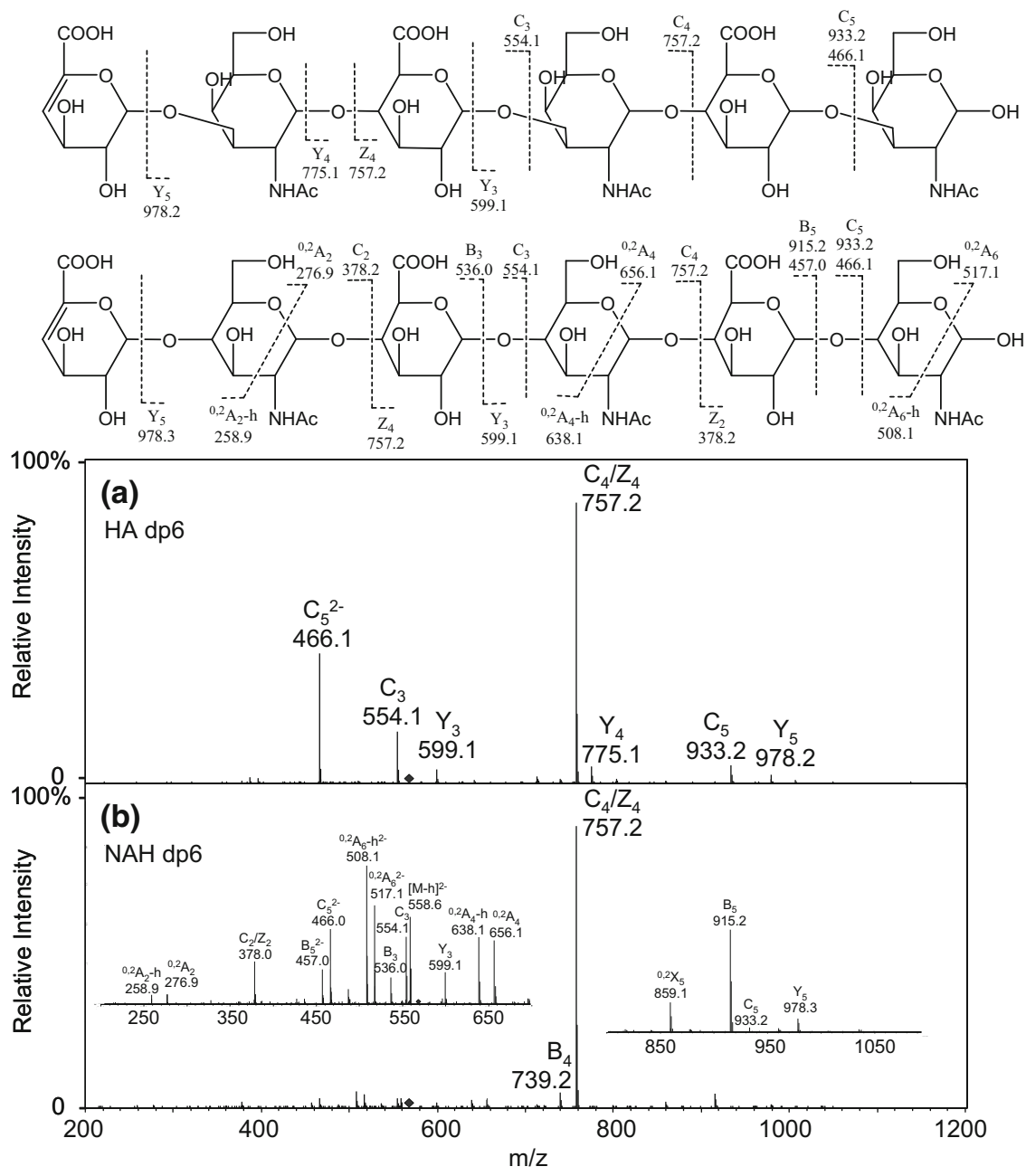

Figure 6. MS/MS spectra of hexasaccharides (dp6) from HA (a) and NAH (b).

ton, DE) equipped with an ion trap, binary pump, and a UV detector. The column was a $5 \mu \mathrm{m}$ Agilent Zorbax SB-C18 $(0.5 \times 250 \mathrm{~mm})$ from Agilent Technologies. Eluent A was water/acetonitrile (85:15), $\mathrm{vol} / \mathrm{vol}$ and Eluent B was water/acetonitrile (35:65) vol/vol. Both eluents contained $12 \mathrm{mM}$ tributylamine (TBA) and 38 $\mathrm{mM} \mathrm{NH} \mathrm{NH}_{4} \mathrm{OAc}$ and their $\mathrm{pH}$ was adjusted to 6.5 with HOAc. The product mixtures of the HA and NAH enzyme digestions were each diluted 10 -fold with water and $1 \mu \mathrm{L}$ of the resulting analytes were individually injected by autosampler. A gradient of $0 \%$ B for $15 \mathrm{~min}$, and $0 \%$ to $100 \%$ B over 85 min was used at a flow rate of $10 \mu \mathrm{l} / \mathrm{min}$. Mass spectra were obtained using an Agilent 1100 series Classic G2445D LC/MSD trap (Agilent Technologies, Inc.). The electrospray interface was set in negative ionization mode with the skimmer potential $-40.0 \mathrm{~V}$, capillary exit $-1200.5 \mathrm{~V}$, and a source temperature of $325^{\circ} \mathrm{C}$ to obtain maximum abundance of the ions in a full scan spectra (150-1500 Da, 10 full scans/s). Nitrogen was used as a drying $(5 \mathrm{~L} / \mathrm{min})$ and nebulizing gas (20 p.s.i.). Auto MS/MS was turned on in these experiments using an estimated cycle time of $0.07 \mathrm{~min}$. Total ion chromatograms (TIC) and mass spectra were processed using Data Analysis 2.0 (Bruker software, Billerica, MA).

\section{Results and Discussion}

Chondroitin lyase $A B C$ was used to digest $\mathrm{HA}$ and heparin lyase III was used to digest NAH and both digestions were carried out to $\sim 30 \%$ completion. The extent of digestion, reflected in the value " $\mathrm{m}$ " (at 100\% digestion $\mathrm{m}=0$ ) was monitored by TLC (Figure 2a). The oligosaccharides resulting from HA had the general structure $\Delta \mathrm{UA}\left(1[\rightarrow 3)\right.$ GlcNAc $(1 \rightarrow 4)$ GlcA $\left.(1]_{\mathrm{m}} \rightarrow 3\right)$ GlcNAc ( $\Delta \mathrm{UA}, 4$-deoxy- $\alpha$-L-threo-hex-4-enopyranosyluronic acid, $\mathrm{m}=0,1,2 \ldots)$. The oligosaccharides resulting from NAH had the general structure $\Delta \mathrm{UA}(1[\rightarrow 4)$ GlcNAc $(1 \rightarrow 4)$ GlcA $\left.(1]_{\mathrm{m}} \rightarrow 4\right)$ GlcNAc.

Next, LC-ESI-MS analysis was performed on HA and $\mathrm{NAH}$ oligosaccharides obtained at $30 \%$ reaction completion (Figure $2 \mathrm{~b}$ and c). Peaks corresponding to a degree of polymerization (dp) from 2 to 20 were observed in the mass spectra of both HA and NAH 
Table 2. Fragment ions observed in the product-ion spectra of HA oligosaccharides

\begin{tabular}{|c|c|c|c|c|c|c|}
\hline & $\mathrm{dp} 2$ & $\mathrm{dp} 4$ & dp6 & dp8 & dp10 & dp12 \\
\hline $\begin{array}{l}0,2 A_{n}{ }^{*} \\
{ }^{0,2} A_{n}-h\end{array}$ & 276.9 & & & & & \\
\hline$B_{n-1}$ & & 536.1 & 915.2 & & & \\
\hline$B_{n-2}$ & & 359.9 & 739.2 & & 1497.5 & \\
\hline$B_{n-3}$ & & & & 915.2 & 1294.3 & \\
\hline$B_{n-4}$ & & & & 739.1 & 1118.3 & 1497.3 \\
\hline$B_{n-5}$ & & & & 536.8 & 915.2 & 1294.3 \\
\hline$B_{n-6}$ & & & & & 739.1 & 1118.3 \\
\hline$B_{n-7}$ & & & & & & 915.2 \\
\hline$C_{n-1}$ & & 554.1 & $933.2 / 466.1$ & $1312.3 / 655.7$ & 845.5 & 1035.5 \\
\hline$C_{n-2} / Z_{n-2}$ & & 378.0 & $757 . .2$ & 1136.3 & 757.2 & 947.2 \\
\hline$C_{n-3}$ & & & 554.1 & 933.2 & 1312.3 & 845.6 \\
\hline$C_{n-4} / Z_{n-4}$ & & & 378.0 & 757.1 & 1136.3 & 757.1 \\
\hline$C_{n-5}$ & & & & 554.1 & 933.2 & 1312.3 \\
\hline$C_{n-6} / Z_{n-6}$ & & & & & 757.2 & 1136.3 \\
\hline$C_{n-7}$ & & & & & & 933.2 \\
\hline$C_{n-8} / Z_{n-8}$ & & & & & & 757.2 \\
\hline$Y_{n-1}$ & & 599.1 & 978.2 & & & \\
\hline$Y_{n-2}$ & & 396.0 & 775.1 & 1154.3 & & \\
\hline$Y_{n-3}$ & & & 599.1 & 978.3 & 1375.4 & \\
\hline$Y_{n-4}^{n-3}$ & & & 396.0 & 775.1 & 1154.3 & \\
\hline$Y_{n-5}$ & & & & 599.1 & 978.3 & 1375.4 \\
\hline$Y_{n-6}$ & & & & & 775.2 & 1154.3 \\
\hline$Y_{n-7}$ & & & & & & 978.3 \\
\hline$Y_{n-8}$ & & & & & & 775.2 \\
\hline
\end{tabular}

${ }^{*} \mathrm{dp}=2 \mathrm{n}$.

oligosaccharides (Table 1). The ESI-MS spectra of HA and NAH oligosaccharides were identical across a range of dp values. For example, the largest oligosaccharides from HA and NAH (dp 20) afforded a calculated mass of 3791.1 based on the fully protonated acidic form. The mass spectra of both showed identical multiply charged molecular ion peaks $[\mathrm{M}-5 \mathrm{H}]^{5-}$ and $[\mathrm{M}-4 \mathrm{H}]^{4-}$ at $m / z 757.3$ and 946.9 , respectively (Figure $3)$, confirming a length of 20 saccharide units.

Tandem mass spectrometry can result in both glycosidic linkage and cross-ring cleavages. All product ions are labeled according to the Domon and Costello nomenclature [31]. The cross-ring cleavages hold the key in distinguishing HA and NAH oligosaccharides. Tandem mass spectra of the smallest products, the two disaccharides (dp2) from HA and $\mathrm{NAH}$, were examined to see if they could be distinguished (Figure 2a and b). Tandem MS, on the singly-charged precursor at $\mathrm{m} / \mathrm{z}$ 378.1 , afforded a cross-ring cleavage ion fragment ${ }^{0,2} \mathrm{~A}_{2}$ at $m / z 276.9$ in both the HA and NAH disaccharides but also a unique ion fragment ${ }^{0,2} \mathrm{~A}_{2}$-h at $m / z 258.9$ in the spectrum of NAH disaccharide, corresponding to a loss of $\mathrm{H}_{2} \mathrm{O}$ from ${ }^{0,2} \mathrm{~A}_{2}$ (Figure 4 ).

The tandem mass spectra of two tetrasaccharides (dp4) were next examined (Figure 5a and b) to determine whether this unique fragment could be used to distinguish oligosaccharides derived HA and NAH. Glycosidic cleavage fragment ions were observed from the singly charged the precursors molecular ions at $\mathrm{m} / \mathrm{z}$ 757.1 for both HA and NAH tetrasaccharides. Again, the cross-ring cleavage ion fragments ${ }^{0,2} \mathrm{~A}_{2}-\mathrm{h} m / z 258.9$ and ${ }^{0,2} \mathrm{~A}_{4}-\mathrm{h} \mathrm{m} / \mathrm{z} 638.1$ were observed only in the NAH. When the tandem MS was performed on the doubly charged molecular ions of the two hexasaccharides (dp6) at $m / z 576.8$ (Figure 6a and b), the fragments observed were similar to those observed in the tandem mass spectra of the $\mathrm{dp} 4[\mathrm{M}-\mathrm{H}]^{-}$precursor. In addition to the glycosidic cleavage ion fragments, observed in tandem mass spectra of both HA and NAH hexasaccharides, A-type ion fragments ${ }^{0,2} \mathrm{~A}_{2},{ }^{0,2} \mathrm{~A}_{4}$, ${ }^{0,2} A_{6},{ }^{0,2} A_{2}-h,{ }^{0,2} A_{4}-h$, and ${ }^{0,2} A_{6}-h$ were also observed in the tandem mass spectrum of the NAH hexasaccharides. The ${ }^{0,2} \mathrm{~A}_{6}$ and ${ }^{0,2} \mathrm{~A}_{6}$-h fragments were mainly observed as doubly charged ions at $m / z 517.1$ and $m / z$ 508.1, respectively. Cross-ring cleavage ion fragments were not observed in spectrum of HA hexasaccharides. In the spectra of HA tetrasaccharide and hexasaccharide, the relative intensities of fragment ions were different. In the spectrum of HA hexasaccharide, the $\mathrm{C}_{3}$ fragment ion at $\mathrm{m} / \mathrm{z} 554.1$ is of much lower intensity than the $C_{3}$ fragment ion in the spectrum of $\mathrm{HA}$ tetrasaccharide (Figures $5 \mathrm{a}$ and $6 \mathrm{a}$ ). The $\mathrm{C}_{4} / \mathrm{Z}_{4}$ fragment ion at $m / z 757.2$ dominates the spectrum of $\mathrm{NAH}$ hexasaccharide, while all the peaks in the spectrum of $\mathrm{NAH}$ tetrasaccharide are of similar relative intensities (Figures $5 \mathrm{~b}$ and $6 \mathrm{~b}$ ). These differences between tetrasaccharide and hexasaccharides would appear to suggest that the charge state influences the product ion pattern. All ion fragments in the tandem mass spectra of dp2 to dp12, derived from $\mathrm{HA}$ and $\mathrm{NAH}$, are presented in 
Table 3. Fragment ions observed in the product-ion spectra of NAH oligosaccharides

\begin{tabular}{|c|c|c|c|c|c|c|}
\hline $\mathrm{dp} \mathrm{n}$ & dp2 & dp4 & dp6 & dp8 & $\mathrm{dp} 10$ & $\mathrm{dp} 12$ \\
\hline$[\mathrm{M}-\mathrm{h}]^{-}$ & 359.9 & 739.1 & 558.1 & 748.2 & 937.8 & \\
\hline $0,2 A_{n}^{*}$ & 276.9 & 656.1 & 517.1 & 706.6 & 896.3 & 723.7 \\
\hline${ }^{0,2} A_{n}-h$ & 258.9 & 638.1 & 508.1 & 697.7 & 887.3 & 717.7 \\
\hline${ }^{0,2} A_{n-2}^{11}$ & & 276.8 & 656.1 & $1035.1 / 517.1$ & $1414.4 / 706.6$ & 896.7 \\
\hline${ }^{0,2} A_{n-2}-h$ & & 258.8 & 638.1 & $1017.1 / 508.1$ & $1396.4 / 697.7$ & 887.7 \\
\hline${ }^{0,2} A_{n-4}$ & & & 276.8 & 656.1 & $1035.1 / 517.1$ & $1414.4 / 706.6$ \\
\hline${ }^{0,2} A_{n-4}-h$ & & & 258.8 & 638.1 & 1017.1/508.1 & $1396.4 / 697.7$ \\
\hline${ }^{0,2} A_{n-6}$ & & & & 276.8 & 656.1 & $1035.1 / 517.1$ \\
\hline${ }^{0,2} A_{n-6}-h$ & & & & 258.8 & 638.1 & 1017.1/508.1 \\
\hline${ }^{0,2} A_{n-8}$ & & & & & 276.8 & 656.1 \\
\hline${ }^{0,2} A_{n-8}-h$ & & & & & 258.8 & 638.1 \\
\hline${ }^{0,2} A_{n-10}$ & & & & & & 276.8 \\
\hline${ }^{0,2} A_{n-10}-h$ & & & & & & 258.8 \\
\hline$B_{n-1}$ & & 536.0 & $915.2 / 457.1$ & & & \\
\hline$B_{n-2}$ & & & 739.2 & 1118.3 & $1497.4 / 748.8$ & \\
\hline$B_{n-3}$ & & & 536.2 & 915.2 & $1294.3 / 646.2$ & \\
\hline$B_{n-4}$ & & & & 739.1 & 1118.3 & 1497.4 \\
\hline$B_{n-5}$ & & & & 536.0 & 915.2 & 1294.3 \\
\hline$B_{n-6}$ & & & & & 739.1 & 1118.2 \\
\hline$B_{n-7}$ & & & & & 536.1 & 915.2 \\
\hline$B_{n-8}$ & & & & & & 739.1 \\
\hline$B_{n-9}$ & & & & & & 536.1 \\
\hline$C_{n-1}$ & & 554.1 & $933.2 / 466.1$ & $1312.3 / 655.7$ & 845.8 & \\
\hline $\mathrm{C}_{\mathrm{n}-2} / \mathrm{Z}_{\mathrm{n}-2}$ & & 378.0 & 757.2 & 1136.3 & 757.2 & 947.2 \\
\hline$C_{n-3}$ & & & 554.1 & 933.2 & $1312.3 / 656.2$ & 845.8 \\
\hline$C_{n-4} / Z_{n-4}$ & & & 378.0 & 757.1 & 1136.3 & 757.1 \\
\hline$C_{n-5}$ & & & & 554.1 & 933.2 & $1312.3 / 656.1$ \\
\hline$C_{n-6} / Z_{n-6}$ & & & & 378.0 & 757.2 & 1136.3 \\
\hline $\mathrm{C}_{\mathrm{n}-7}$ & & & & & & 933.2 \\
\hline$C_{n-8} / Z_{n-8}$ & & & & & & 757.2 \\
\hline$Y_{n-1}$ & & 599.1 & 978.2 & & & \\
\hline$Y_{n-2}$ & & & 775.1 & 1154.3 & & \\
\hline$Y_{n-3}$ & & & 599.1 & 978.3 & 1375.4 & \\
\hline$Y_{n-4}$ & & & 396.0 & 775.1 & 1154.3 & \\
\hline$Y_{n-5}$ & & & & 599.1 & 978.3 & 1375.4 \\
\hline$Y_{n-6}$ & & & & 396.0 & 775.2 & 1154.3 \\
\hline$Y_{n-7}$ & & & & & & 978.3 \\
\hline$Y_{n-8}$ & & & & & & 775.2 \\
\hline
\end{tabular}

${ }^{*} \mathrm{dp}=2 \mathrm{n}$.

Table 2 and Table 3, respectively. Tandem MS was performed on singly or multiply charged molecular ions (labeled with asterisks in Table 1$)^{0,2} \mathrm{~A}$-type ion fragments were observed in the GlcNAc residue of $\mathrm{NAH}$ oligosaccharides, but were not observed in the GlcNAc residues of HA oligosaccharides. The larger oligosaccharides of HA and NAH from dp14 to dp20 shown in the TIC (Figure 2) have a similar fragmentation to that of smaller oligosaccharides, dp2 to dp 12, in which the difference between $\mathrm{HA}$ and NAH also could be observed (data not shown). Interestingly, only dp 2 of HA gave an ${ }^{0,2} \mathrm{~A}$ fragment (but not an ${ }^{0,2} \mathrm{~A}-\mathrm{h}$ fragment), making ${ }^{0,2} \mathrm{~A}-\mathrm{h}$ fragment a unique marker for NAH.

Ion fragments of the ${ }^{0,2} \mathrm{~A}$-type observed in the NAH GlcNAc residues containing $1 \rightarrow 4$ linkage suggest the fragmentation mechanism is a retro-aldol rearrangement of oligosaccharide ions in the negative mode [32-35]. This mechanism requires an open-ring reducing terminal aldehyde, and such structures are formed by C-type fragmentation [34-38]. The ${ }^{0,2} \mathrm{~A}_{\mathrm{n}}(\mathrm{n}=$ even number) ions formed from cross-ring cleavage to the internal glucosamine residues are therefore likely to arise from the $C_{n}(n=$ even number $)$ ions by retro-aldol rearrangement. These A-type fragment ions are observed in residues that are 4- or 6- linked [21, 34, 36-42]. Furthermore, in NAH oligosaccharides, the free hydroxy group at position 3 can accept a proton from position 4 after cleavage of the GlcNAc ring by ${ }^{0,2} \mathrm{~A}$ type fragmentation affording water and the negatively charged ${ }^{0,2} \mathrm{~A}_{\mathrm{n}}-\mathrm{h}$ fragment. These dehydrated A-type fragment ions also are observed with the residue requiring an unsubstituted hydroxyl in the 3 position in other oligosaccharides [34, 36, 39, 43]. In the HA oligosaccharides, the bonds at $\mathrm{C}-3$ of GlcNAc are substituted perhaps making these more stable than NAH oligosaccharides. The exception to this rule is dp2 from HA, where the ${ }^{0,2} \mathrm{~A}_{2}$ ion fragment is observed. This may result from the small size of the dp 2 molecule, preventing it from dissipating vibrational energy, resulting in 
its fragmentation. Despite its small size, the HA disaccharide still fails to afford a ${ }^{0,2} \mathrm{~A}_{\mathrm{n}}$-h fragment ion because of its substitution at position 3 . Here, the presence of ${ }^{0,2} \mathrm{~A}$-type fragment ions can be used as a diagnostic tool to distinguish HA disaccharide from longer HA oligosaccharides, in cases where the charge state is unknown.

In conclusion, the current study clearly demonstrates LC-MS/MS can be used to differentiate HA and NAH oligosaccharides. The sensitivity of this method is better than $100 \mathrm{ng}$ for each oligosaccharide separated using RPIP-HPLC. A-type fragment ions from GlcNAc residues were shown as diagnostic peaks in MS/MS spectra of NAH oligosaccharides, but not in the spectra of $\mathrm{HA}$ oligosaccharides. One exception was a ${ }^{0,2} \mathrm{~A}_{2}$ ion fragment observed for the disaccharide from HA. This approach should be useful for screening the capsules of bacterial isolates to determine whether they are composed of HA or NAH polysaccharides. This method might also be useful in distinguishing between small quantities of $\mathrm{HA}$ and NAH derived oligosaccharides isolated from animal tissues. It should also be useful as a complement approach to confirm the structure of unsulfated chondroitin oligosaccharides that have the same linkage pattern as HA, containing 3-linked HexNAc residues.

\section{Acknowledgments}

The authors thank Tatiana Laremore for her careful reading of the manuscript and the NIH for supporting this research through grants GM38060 and HL62244.

\section{References}

1. Wu, Z. L.; Zhang, L.; Beeler, D. L.; Kuberan, B.; Rosenberg, R. D. A new strategy for defining critical functional groups on heparan sulfate. FASEB J. 2002, 16, 539-545.

2. Capila, I.; Linhardt, R. J. Heparin-protein interactions. Angew. Chem. Int. Ed. Engl. 2002, 41, 391-412.

3. Bernfield, M.; Gotte, M.; Park, P. W.; Reizes, O.; Fitzgerald, M. L.; Lincecum, J.; Zako, M. Functions of cell surface heparan sulfate proteoglycans. Annu. Rev. Biochem. 1999, 68, 729-777.

4. Taylor, K. R.; Gallo, R. L. Glycosaminoglycans and their proteoglycans: Host-associated molecular patterns for initiation and modulation of inflammation. FASEB J. 2006, 20, 9-22.

5. Sasisekharan, R.; Raman, R.; Prabhakar, V. Glycomics approach to structure-function relationships of glycosaminoglycans. Annu. Rev. Biomed. Eng. 2006, 8, 181-231.

6. Meyer, K. The mucopolysaccharides of the interfibrillar substance of the mesenchyme. Ann. N.Y. Acad. Sci. 1950, 52, 961-963.

7. Lindahl, U.; Kusche-Gullberg, M.; Kjellen, L. Regulated diversity of heparan sulfate. J. Biol. Chem. 1998, 273, 24979-24982.

8. DeAngelis, P. L.; Papaconstantinou, J.; Weigel, P. H. Molecular cloning, identification, and sequence of the hyaluronan synthase gene from group A Streptococcus pyogenes. J. Biol. Chem. 1993, 268, 19181-19184.

9. Widner, B.; Behr, R.; Von Dollen, S.; Tang, M.; Heu, T.; Sloma, A. Sternberg, D.; Deangelis, P. L.; Weigel, P. H.; Brown, S. Hyaluronic acid production in Bacillus subtilis. Appl. Environ. Microbiol. 2005, 71, 37473752 .

10. Esslinger, J.; Seleim, R. S.; Blobel, H. Adhesion of Pasteurella multocida to HeLa cells and to macrophages of different animal species.Rev. Med. Veterinaire14549199453

11. Vann, W. F.; Schmidt, M. A.; Jann, B.; Jann, K. The structure of the capsular polysaccharide (K5 antigen) of urinary tract infective Escherichia coli 010:K5:H4. A polymer similar to desulfo-heparin. Eur. J. Biochem.1163591981364

12. Murphy, K. J.; Merry, C. L.; Lyon, M.; Thompson, J. E.; Roberts, I. S.; Gallagher, J. T. A new model for the domain structure of heparan sulfate based on the novel specificity of K5 lyase. J. Biol. Chem. 2004, 279, $27239-27245$.
13. Born, J.; Jann, K.; Assmann, K. J.; Lindahl, U.; Berden, J. H. N-acetylated domains in heparan sulfates revealed by a monoclonal antibody against the Escherichia coli K5 capsular polysaccharide. Distribution of the cognate epitope in normal human kidney and transplant kidney with chronic vascular rejection. J. Biol. Chem. 1996, 271, 22802-22809.

14. Razi, N.; Feyzi, E.; Bjork, I.; Naggi, A.; Casu, B.; Lindahl, U. Structural and functional properties of heparin analogues obtained by chemical sulphation of Escherichia coli K5 capsular polysaccharide. Biochem. J. 1995, 309 (part 2), 465-472.

15. Lindahl, U.; Li, J. P.; Kusche-Gullberg, M.; Salmivirta, M.; Alaranta, S. Veromaa, T.; Emeis, J.; Roberts, I.; Taylor, C.; Oreste, P.; Zoppetti, G.; Naggi, A.; Torri, G.; Casu, B. Generation of "neoheparin" from E. coli K5 capsular polysaccharide. J. Med. Chem. 2005, 48, 349-352.

16. Leali, D.; Belleri, M.; Urbinati, C.; Coltrini, D.; Oreste, P.; Zoppetti, G.; Ribatti, D.; Rusnati, M.; Presta, M. Fibroblast growth factor-2 antagonist activity and angiostatic capacity of sulfated Escherichia coli $\mathrm{K} 5$ polysaccharide derivatives. I. Biol. Chem. 2001, 276, 37900-37908.

17. Kuberan, B.; Beeler, D. L.; Lawrence, R.; Lech, M.; Rosenberg, R. D. Rapid two-step synthesis of mitrin from heparosan: A replacement for heparin. J. Am. Chem. Soc. 2003, 125, 12424-12425.

18. Banerii, S.; Wright, A. J.; Noble, M.; Mahoney, D. J.; Campbell, I. D.; Day, A. J.; Jackson, D. G. Structures of the Cd44-hyaluronan complex provide insight into a fundamental carbohydrate-protein interaction. Nat. Struct. Mol. Biol. 2007, 14, 234-239.

19. Seyfried, N. T.; McVey, G. F.; Almond, A.; Mahoney, D. J.; Dudhia, J.; Day, A. J. Expression and purification of functionally active hyaluronan-binding domains from human cartilage link protein, aggrecan and versican: Formation of ternary complexes with defined hyaluronan oligosaccharides. J. Biol. Chem. 2005, 280, 5435-5448.

20. Blundell, C. D.; Mahoney, D. J.; Almond, A.; DeAngelis, P. L.; Kahmann, J. D.; Teriete, P.; Pickford, A. R.; Campbell, I. D.; Day, A. J. The link module from ovulation- and inflammation-associated protein TSG-6 changes conformation on hyaluronan binding. J. Biol. Chem. 2003, 278, 49261-49270.

21. Zaia, J. Mass spectrometry of oligosaccharides. Mass Spectrom. Rev. 2004, 23, 161-227.

22. Chi, L.; Amster, J.; Linhardt, R. J. Mass spectrometry for the analysis of highly charged sulfated carbohydrate. Current. Anal. Chem. 2005, 1, 223-240.

23. Storm, T.; Reemtsma, T.; Jekel, M. Use of volatile amines as ion-pairing agents for the high-performance liquid chromatographic-tandem mass spectrometric determination of aromatic sulfonates in industrial waste water. J. Chromatogr. A 1999, 854, 175-185.

24. Guan, F.; Ishii, A.; Seno, H.; Watanabe-Suzuki, K.; Kumazawa, T.; Suzuki, O. Use of an ion-pairing reagent for high-performance liquid chromatography-atmospheric pressure chemical ionization mass spectrometry determination of anionic anticoagulant rodenticides in body fluids. J. Chromatogr. B Biomed. Sci. Appl. 1999, 731, 155-165.

25. Kuberan, B.; Lech, M.; Zhang, L.; Wu, Z. L.; Beeler, D. L.; Rosenberg, R. D. Analysis of heparan sulfate oligosaccharides with ion pair-reverse phase capillary high performance liquid chromatography-microelectrospray ionization time-of-flight mass spectrometry. J. Am. Chem. Soc. 2002, 124, 8707-8718

26. Minamisawa, T.; Suzuki, K.; Kajimoto, N.; Iida, M.; Maeda, H.; Hirabayashi, J. Microscale preparation of even- and odd-numbered $\mathrm{N}$-acetylheparosan oligosaccharides. Carbohydr. Res. 2006, 341, 230-237.

27. Blundell, C. D.; Reed, M. A.; Almond, A. Complete assignment of hyaluronan oligosaccharides up to hexasaccharides. Carbohydr. Res. 2006, 341, 2803-2815.

28. Kuhn, A. V.; Ruttinger, H. H.; Neubert, R. H.; Raith, K. Identification of hyaluronic acid oligosaccharides by direct coupling of capillary electrophoresis with electrospray ion trap mass spectrometry. Rapid Commun. Mass Spectrom. 2003, 17, 576-582.

29. Kuhn, A. V.; Raith, K.; Sauerland, V.; Neubert, R. H. Quantification of hyaluronic acid fragments in pharmaceutical formulations using LCESI-MS. J. Pharm. Biomed. Anal. 2003, 30, 1531-1537.

30. Zhang, Z.; Yu, G.; Zhao, X.; Liu, H.; Guan, H.; Lawson, A. M.; Chai, W. Sequence analysis of alginate-derived oligosaccharides by negative-ion electrospray tandem mass spectrometry. J. Am. Soc. Mass Spectrom. 2006, 17, 621-630.

31. Domon, B.; Costello, C. E. A systematic nomenclature for carbohydrate fragmentations in FAB-MS/MS spectra of glycoconjugates. Glycoconj. J. 1988, 5, 397-409.

32. Spengler, B.; Dolce, J. W.; Cotter, R. J. Infrared-Laser Desorption Mass-Spectrometry of Oligosaccharides-Fragmentation Mechanisms and Isomer Analysis. Anal. Chem. 1990, 62, 1731-1737.

33. Dallinga, J. W.; Heerma, W. Reaction mechanism and fragment ion structure determination of deprotonated small oligosaccharides, studied by negative ion fast atom bombardment (tandem) mass spectrometry. Biol. Mass Spectrom. 1991, 20, 215-231.

34. Zaia, J.; Miller, M. J.; Seymour, J. L.; Costello, C. E. The role of mobile protons in negative ion CID of oligosaccharides. J. Am. Soc. Mass Spectrom. 2007, 18, 952-960.

35. Von Seggern, C. E.; Zarek, P. E.; Cotter, R. J. Fragmentation of sialylated carbohydrates using infrared atmospheric pressure MALDI ion trap mass spectrometry from cation-doped liquid matrixes. Anal. Chem. 2003, $75,6523-6530$.

36. Chai, W.; Piskarev, V.; Lawson, A. M. Negative-ion electrospray mass spectrometry of neutral underivatized oligosaccharides. Anal. Chem. 2001, 73, 651-657. 
37. Pfenninger, A.; Karas, M.; Finke, B.; Stahl, B. Structural analysis of underivatized neutral human milk oligosaccharides in the negative ion mode by nano-electrospray MS(n). Part 1: Methodology. J. Am. Soc. Mass Spectrom. 2002, 13, 1331-1340.

38. Pfenninger, A.; Karas, M.; Finke, B.; Stahl, B. Structural analysis of underivatized neutral human milk oligosaccharides in the negative ion mode by nano-electrospray MS(n). Part 2: Application to isomeric mixtures. J. Am. Soc. Mass Spectrom. 2002, 13, 1341-1348.

39. Chai, W.; Piskarev, V.; Lawson, A. M. Branching pattern and sequence analysis of underivatized oligosaccharides by combined MS/MS of singly and doubly charged molecular ions in negative-ion electrospray mass spectrometry. J. Am. Soc. Mass Spectrom. 2002, 13, $670-679$.
40. Harvey, D. J. Fragmentation of negative ions from carbohydrates: Part 3. Fragmentation of hybrid and complex N-linked glycans. J. Am. Soc Mass Spectrom. 2005, 16, 647-659.

41. Harvey, D. J. Fragmentation of negative ions from carbohydrates: Part 2. Fragmentation of high-mannose N-linked glycans. J. Am. Soc. Mass Spectrom. 2005, 16, 631-646.

42. Saad, O. M.; Myers, R. A.; Castleton, D. L.; Leary, J. A. Analysis of hyaluronan content in chondroitin sulfate preparations by using selective enzymatic digestion and electrospray ionization mass spectrometry. Anal. Biochem. 2005, 344, 232-239.

43. Zhang, Y.; Kariya, Y.; Conrad, A. H. Tasheva, E. S.; Conrad, G. W. Analysis of keratan sulfate oligosaccharides by electrospray ionization tandem mass spectrometry. Anal. Chem. 2005, 77, 902-910. 